\section{Dementia

Dement Geriatr Cogn Disord 2019;47:345-354

\title{
Assessment of Visual Association Memory in Low-Educated, Non-Western Immigrants with the Modified Visual Association Test
}

\author{
Sanne Franzen ${ }^{a} \quad E^{2}$ ther van den Berg ${ }^{a} \quad$ Yuled Kalkisim ${ }^{a}$ b Lotte van de Wiel $^{b}$ \\ Marleen Harkes $^{c}$ Rozemarijn L. van Bruchem-Visser ${ }^{d}$ Frank Jan de Jong ${ }^{a}$ \\ Lize C. Jiskoot ${ }^{a}$ Janne M. Papma ${ }^{a}$ \\ aDepartment of Neurology, Erasmus MC University Medical Center, Rotterdam, \\ The Netherlands; ${ }^{b}$ Department of Medical Psychology, Maasstad Ziekenhuis, Rotterdam, \\ The Netherlands; ' Department of Geriatric Medicine, Maasstad Ziekenhuis, Rotterdam, \\ The Netherlands; ${ }^{\mathrm{d}}$ Department of Internal Medicine, Erasmus MC University \\ Medical Center, Rotterdam, The Netherlands
}

\section{Keywords}

Alzheimer's disease - Dementia - Neurodegenerative diseases - Cross-cultural comparison · Literacy · Education · Cognition

\begin{abstract}
Background: Neuropsychological tests are influenced by culture, language, level of education, and literacy, but there are few cognitive tests of which the applicability in ethnic minority populations has been studied. Objectives: The aim of this study was to assess the reliability and validity of the Visual Association Test (VAT), a test of visual association memory, in a non-Western, low-educated memory clinic population. Additionally, a modified version of the VAT using colored photographs instead of line drawings was studied (mVAT). Method: Both the original VAT and the mVAT were administered to non-Western immigrants $(n=73)$ from 2 multicultural memory clinics in Rotterdam, The Netherlands, and a control sample of nondemented Turkish elderly $(n=14)$ with low education levels (32 and 29\% illiterate, respectively). Results: Both the VAT and the mVAT were able to discriminate persons with and without dementia (area under the curve: VAT, 0.77-0.88; mVAT, 0.85-0.95). The mVAT had more homogeneous item difficulty levels than the VAT. Administration of parallel versions of the VAT and the mVAT within the same person revealed higher scores on the mVAT $(Z=-3.35$, $p=0.001)$. Conclusions: The mVAT is a reliable and valid measure of memory in non-Western immigrants. Clinicians and researchers should be aware that the memory performance of immigrants may be systematically underestimated when using tests with black-and-white line drawings, such as the original VAT.


Franzen et al.: Assessment of Visual Association Memory with the Modified VAT

\section{Introduction}

Neuropsychological examination is fundamental to the assessment of dementia. Neuropsychological test performance is known to be substantially affected by culture, language, (quality of) education, and literacy [1-8]. For example, healthy illiterate persons have lower scores on visual naming tests using black-and-white line drawings than literate persons [912]. This difference disappears when colored photographs are used [10], which is most likely related to the higher level of detail provided by the colored photographs [13]. This example illustrates how tests developed for educated, Western people cannot readily be used in other populations. In recent years, new screening instruments for dementia, such as the CrossCultural Dementia Screening or CCD [14] and the Rowland Universal Dementia Assessment Scale or RUDAS [15-18], have therefore been developed and validated for ethnic minority populations. These instruments are designed to screen for dementia. However, domainspecific neuropsychological tests that can determine the underlying etiology are lacking.

The Visual Association Test (VAT) [19] is a test of visual association memory that is particularly able to discriminate between Alzheimer's disease (AD) and other types of dementia, as performance is associated with atrophy of the medial temporal lobe [20]. In the VAT, patients are required to remember two interacting objects (such as a stroller with a bird in it, or a monkey with an umbrella) presented in the form of black-and-white line drawings. Although this test is frequently used in clinical practice and was previously recommended as best practice in the neuropsychological assessment of non-Western immigrants [21], the reliability and validity of the VAT have not been assessed in an ethnic minority population or in people who are illiterate.

Given the above mentioned difficulties regarding the naming of black-and-white line drawings in healthy illiterate people, the question can be raised of whether the VAT puts illiterate or low-educated patients at a disadvantage, for example due to difficulties recognizing and thus remembering the objects. These difficulties may also pose a threat to the validity of the VAT as a measure of visual association memory in these persons. We hypothesize that people who are low educated could benefit from a test that uses colored photographs instead of black-and-white line drawings. The aims of this study were to examine the reliability and validity of the original version of the VAT and a modified version using colored photographs (mVAT) and to compare performance on both tests in a population of low-educated nonWestern immigrants.

\section{Materials and Methods}

\section{Participants}

Seventy-three non-Western immigrant patients who visited the outpatient multicultural memory clinics of the Erasmus MC University Medical Center and the former Havenziekenhuis in Rotterdam, The Netherlands, were included between April 2016 and October 2018. The patients had immigrated from Turkey ( $n=$ $34)$, Morocco $(n=13)$, Cape Verde $(n=10)$, Pakistan $(n=4)$, Iraq $(n=2)$, Afghanistan $(n=2)$, the State of Palestine $(n=1)$, Syria $(n=1)$, Egypt $(n=1)$, China $(n=1)$, Venezuela $(n=1)$, the Dutch Antilles $(n=1)$, Suriname $(n=1)$, and Macedonia $(n=1)$. The diagnostic workup consisted of a comprehensive clinical evaluation, with history taking by a geriatrician or neurologist, a neuropsychological assessment, laboratory screening with blood tests, and (in a subset of patients) structural brain imaging (computed tomography, $n=23$; magnetic resonance imaging, $n=25$ ). Diagnosis was determined in a multidisciplinary consensus meeting which included a neuropsychologist, a neurologist, a radiologist, and a geriatrician, using the diagnostic research criteria for dementia subtypes [22-24].

Fourteen healthy Turkish community-dwelling individuals were included as a control group. The inclusion criteria for the control group were: age $>50$ years, free of self-reported cognitive complaints, and a RUDAS [15] score $\geq 23$. For 9 healthy controls, informants filled out the short IQ-code [25], confirming the 
Fig. 1. Association card from the VAT and its adaptation for the mVAT (reprinted with permission from the Hogrefe Publishing Group).

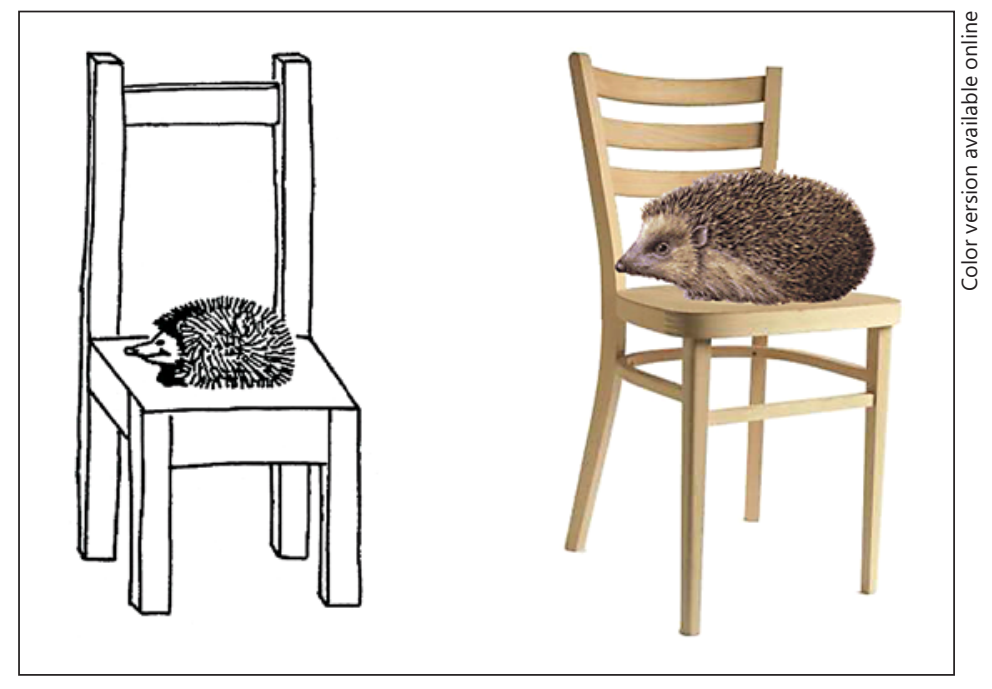

patient's self-reported absence of cognitive complaints. In the other cases, no informant was available. All healthy controls provided a written informed consent. They were recruited in an urban area through centers providing activities for Turkish elderly and through the personal networks of included participants.

\section{Measures}

The Original VAT

In the original VAT, patients are asked to name 6 stimuli on consecutive black-and-white line drawings (the cue cards) presented in a paper booklet. Patients are then shown cards on which the previous stimuli are interacting with new stimuli, and they are asked to name both items on each consecutive card. Patients are then again shown the initial cue cards and asked to name the missing item. This procedure is repeated in trial 2 (unless there is a maximum score on the first trial). Naming errors are allowed as long as the names are specific enough to be identified as correct or incorrect in the reproduction trial, i.e. "prickly animal," "prickly thing," or even "brush" would be sufficiently specific to indicate a hedgehog and would thus be considered correct.

\section{Modification of the VAT}

To create a photograph version of the VAT, henceforth called the modified VAT (i.e., mVAT), all blackand-white line drawings from the original VAT were replaced with colored photographs of the same objects (Fig. 1). No other changes were made to the test. Stimuli were presented on A5-sized booklets, similar to the original VAT. The original VAT has multiple parallel versions. Therefore, modifications of both the original VAT version A and the parallel version B were made.

\section{Other Cognitive Tests}

The patients were tested with the CCD [14], a comprehensive screening test for dementia, assessing the domains of memory, mental speed, and executive functioning. It was specifically developed and validated for a large sample of immigrants in The Netherlands, and normative data are available. Furthermore, patients were administered the RUDAS [15] and/or the Mini Mental State Examination (MMSE) [26]. In some patients, other tests, such as the Location Learning Test [27] $(n=15)$ and category verbal fluency (supermarket) $(n=$ $10)$, were administered as well.

\section{Procedure}

All participants from the outpatient clinic underwent a neuropsychological examination. Interpreters were present during these examinations, as well as during the intake interview, for all participants who were insufficiently fluent in Dutch $(96 \%, n=70)$. The administration procedures for the VAT (and thus the mVAT) according to the test manual [19] were followed, including prorating of the second trial. The administration time of the VAT (and the mVAT) is approximately $5 \mathrm{~min}$. As the stimuli were identical for both the VAT and the mVAT (apart from line drawings vs. photographs), patients could not be administered version A of both the VAT and the mVAT. Therefore, all patients were administered either VAT version A and mVAT version B 
Franzen et al.: Assessment of Visual Association Memory with the Modified VAT

Table 1. Demographic characteristics, cognitive test scores, and group comparisons for the whole sample

\begin{tabular}{lcc}
\hline & $\begin{array}{c}\text { Controls } \\
(n=14)\end{array}$ & $\begin{array}{c}\text { Memory clinic } \\
\text { patients }(n=73)\end{array}$ \\
\hline Age, years & $62.21 \pm 11.49$ & $68.48 \pm 11.00$ \\
Education & & $23(32)$ \\
$\quad 0$ years of education/illiterate & $4(29)$ & $27(37)$ \\
$\quad$ year of education up to primary education & $6(43)$ & $21(29)$ \\
$\quad$ primary education & $4(29)$ & 55 \\
Male gender, \% & 21 & $38.5 \pm 7.4$ \\
Time in The Netherlands, years & $36.9 \pm 16.3$ & $22.1 \pm 5.0^{\mathrm{a}}$ \\
RUDAS & $26.86 \pm 1.92$ & $16.6 \pm 5.8^{\mathrm{b}}$ \\
MMSE & - & $113.2 \pm 9.6$ \\
CCD objects test Ac & - & $104.7 \pm 12.2$ \\
CCD objects test B & - & $13(18)$ \\
Diagnosis, $n$ (\%) & - & $13(18)$ \\
Subjective memory complaints & - & $22(30)$ \\
Mild cognitive impairment & - & $8(11)$ \\
Dementia (AD, VaD, mixed, and other) & - & $7(10)$ \\
Primary psychiatric disorder (e.g., depression) & - & $10(14)$ \\
Cognitive disorder due to another known medical condition & - & $n$
\end{tabular}

VaD, vascular dementia. Values are displayed as means \pm SD or numbers (\%) unless otherwise specified. ${ }^{\text {a }} n=26$ patients. ${ }^{\mathrm{b}} n=54$ patients. ${ }^{\mathrm{c}}$ The maximum score for the objects test A (immediate recognition) and B (delayed recognition) is 122 . The general cut-offs for dementia are $\leq 118$ for objects test $A$ and $\leq 109$ for objects test $\mathrm{B}$.

or VAT version B and mVAT version A. In the majority of cases, the mVAT was administered before the VAT to ensure that a higher score on the mVAT was not caused by the participant being aware at the first trial that the stimuli needed to be remembered. In a subset of patients, this order was reversed.

Control participants were assessed in Turkish, either at home or at the day activity center, by a neuropsychologist who is a native speaker of Turkish (Y.K.). Similar to the patients, the order of administration of the VAT versus the mVAT, as well as the versions that were used, was varied.

\section{Statistical Analysis}

Differences in demographic characteristics were analyzed with $\chi^{2}$ tests for nominal data and $t$ tests for continuous data. Cronbach's $\alpha$ and item-total correlations were used to determine the internal consistency, and Cochran $Q$ tests were used to assess item difficulty levels. For reliability analyses, both parallel versions of the VAT and the mVAT were analyzed separately. For all other analyses, parallel versions A and B of the original and A and B of the mVAT were merged. As the scores of both the VAT and the mVAT were not normally distributed, a Wilcoxon signed-rank test was used to analyze intraindividual differences in the performance on the mVAT versus the VAT. Spearman correlations were used for correlational analyses to determine the convergent validity and the relationship with demographic variables. Receiver operating characteristic curves were used to assess diagnostic accuracy. In secondary analyses differences were analyzed in participants with a low education level (less than primary school) versus participants who had received more education (primary school and up).

\section{Results}

As is shown in Table 1, controls were more often female, but the groups did not differ in terms of age, years of residence in The Netherlands, or level of education. For 14\% of the patients in the sample, the diagnosis could not be determined definitively with the current 
Table 2. Item-total Spearman's correlations and Cronbach's $\alpha$ for the first trial of all versions

\begin{tabular}{lllll}
\hline & $\begin{array}{l}\text { Trial 1 mVAT A } \\
(n=32)\end{array}$ & $\begin{array}{l}\text { Trial 1 mVAT B } \\
(n=55)\end{array}$ & $\begin{array}{l}\text { Trial 1 VAT A } \\
(n=55)\end{array}$ & $\begin{array}{l}\text { Trial 1 VAT B } \\
(n=25)\end{array}$ \\
\hline Item 1 $(\rho)$ & 0.64 & 0.77 & 0.61 & 0.57 \\
Item 2 $(\rho)$ & 0.57 & 0.59 & 0.59 & 0.60 \\
Item 3 $(\rho)$ & 0.54 & 0.74 & 0.72 & 0.50 \\
Item 4 $(\rho)$ & 0.46 & 0.73 & 0.68 & $0.34(\mathrm{~ns})$ \\
Item 5 $(\rho)$ & 0.56 & 0.73 & 0.68 & 0.69 \\
Item 6 $(\rho)$ & 0.67 & 0.68 & 0.71 & $0.18(\mathrm{~ns})$ \\
Cronbach's $\alpha$ & 0.63 & 0.81 & 0.75 & 0.41 \\
\hline
\end{tabular}

All correlations are significant at $p<0.05$ unless otherwise specified.

Table 3. Percent correct per item of mVAT A and B and VAT A and B

\begin{tabular}{|c|c|c|c|c|c|}
\hline & $\begin{array}{l}\text { mVAT A trial } \\
1\end{array}$ & $\begin{array}{l}\text { VAT A trial } \\
1\end{array}$ & & $\begin{array}{l}\text { mVAT B trial } \\
1\end{array}$ & $\begin{array}{l}\text { VAT B trial } \\
1\end{array}$ \\
\hline A item 1 & 69 & 55 & B item 1 & 62 & 64 \\
\hline A item 2 & 75 & 54 & B item 2 & 68 & 28 \\
\hline A item 3 & 72 & 64 & B item 3 & 66 & 44 \\
\hline A item 4 & 60 & 44 & B item 4 & 64 & 72 \\
\hline A item 5 & 75 & 56 & B item 5 & 36 & 64 \\
\hline A item 6 & 53 & 56 & B item 6 & 64 & 24 \\
\hline
\end{tabular}

Values are presented as percents.

diagnostic procedures, or additional procedures to determine the diagnosis, such as a lumbar puncture, failed or were refused by the patient. These patients remained in the analyses. All of the included patients and controls had normal or corrected-to-normal vision. None of the patients or controls reported color blindness.

\section{Reliability}

Internal Consistency

The first trial of VAT version A displayed a Cronbach's $\alpha$ of 0.75 , while the first trial of VAT version B had a Cronbach's $\alpha$ of 0.41 (Table 2). Cronbach's $\alpha$ for the first trial of mVAT version A was 0.63 , and Cronbach's $\alpha$ was 0.81 for the first trial of mVAT version B. Item-total correlations were strong for the mVAT, as well as for VAT version A (Table 2). VAT version B, however, had 2 items with nonsignificant correlations with the total score for trial 1.

\section{Item Difficulty}

Table 3 shows the percentage of people who remembered an item correctly at the first trial of the VAT and mVAT versions A and B. Overall, the item difficulty was lower for the mVAT than for the VAT, without reaching ceiling effects. Item difficulty levels were homogeneous for VAT version A and mVAT version A. Heterogeneity in item difficulty levels was observed for VAT version B (Cochran's $Q=24.8$, d.f. $=5, p<0.001$ ). Version B of the mVAT did not have homogeneous difficulty levels either (Cochran's $Q=22.0$, d.f. $=5, p=0.001$ ), as item 5 (leaf-syringe) was more difficult than the other items, but after deleting this item the test was homogeneous (Cochran's $Q=0.7, p=\mathrm{ns}$ ). 

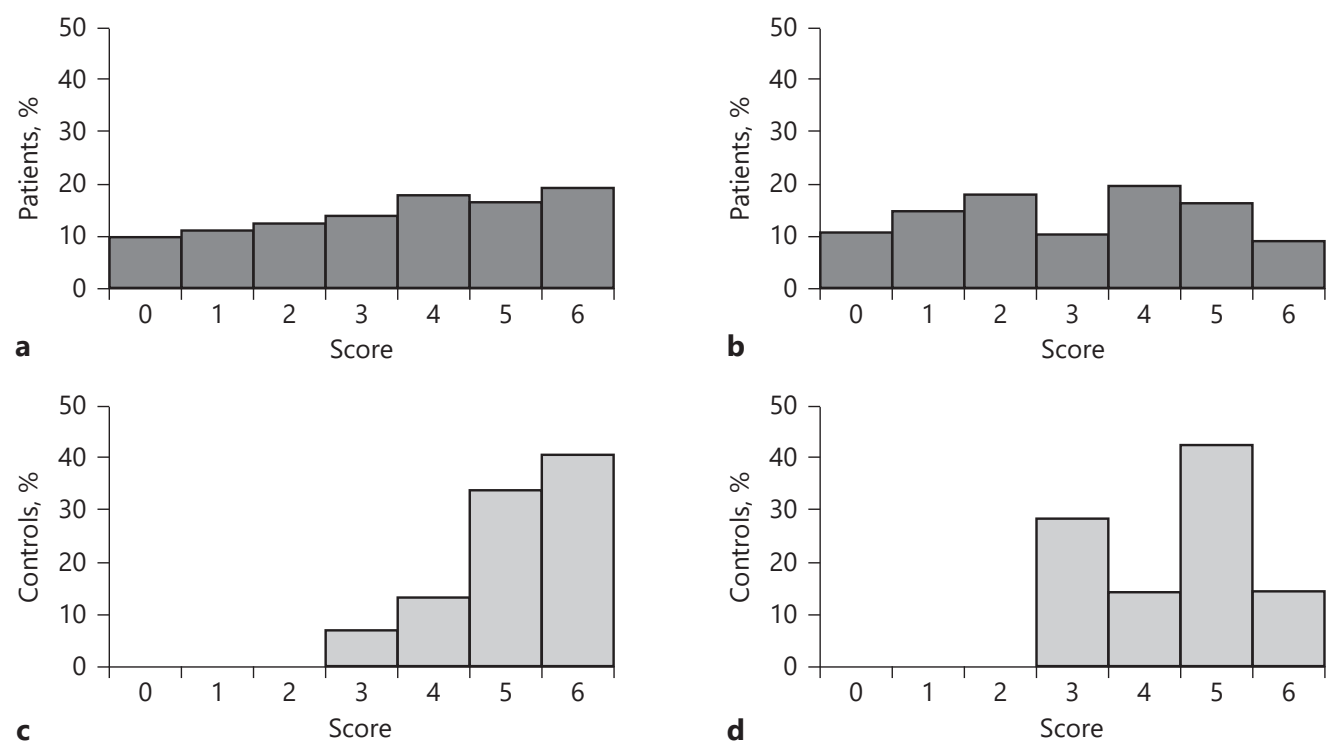

Fig. 2. Scores on the first trial of the mVAT (a, c) and VAT (b, d) for patients (dark gray) and controls (light gray).
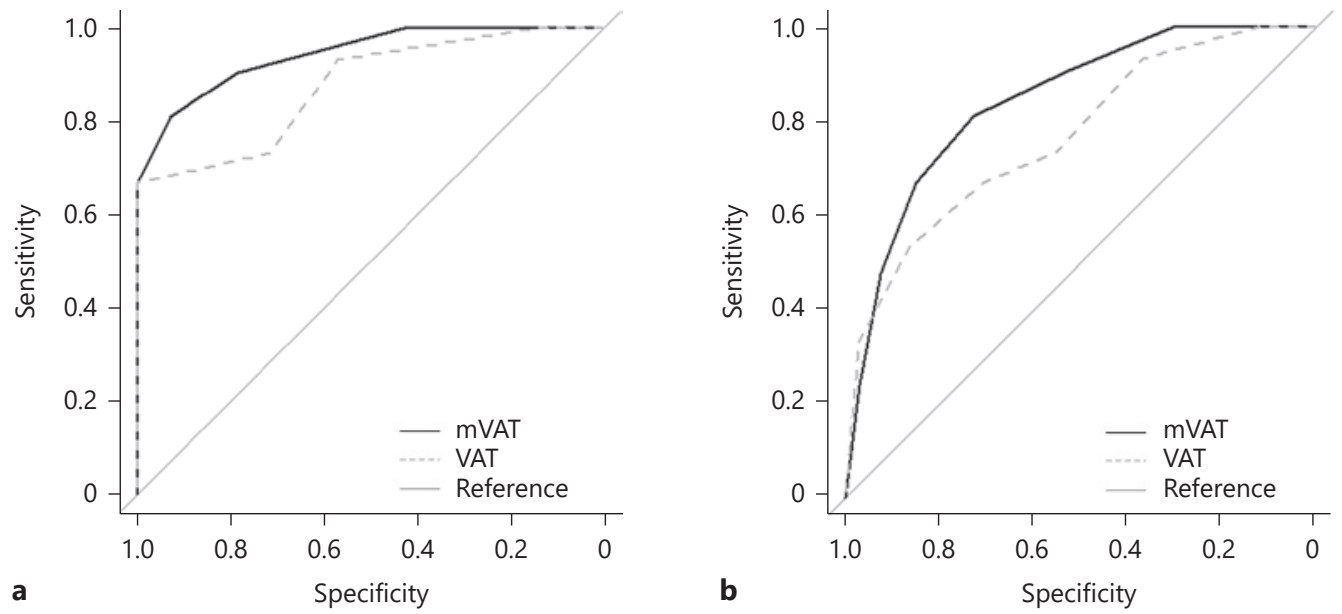

Fig. 3. Receiver operating characteristic curves for the mVAT and the VAT for controls vs. dementia patients (a) and dementia patients vs. the rest of the sample, including controls (b).

For the distribution of the scores in the first trial for patients and controls, see Figure 2. There were 324 correct responses in the first trial of the mVAT $(n=87)$; of the subjects who also completed trial 2, there were 304 cases followed by a correct response on the same item in the second trial (93.8\%). Similarly, on the VAT, 260 correct responses were recorded for the first trial $(n=81), 250$ cases $(96.2 \%)$ of which were followed by a correct response on the same item in the next trial. 
Table 4. Correlation of mVAT trial 1 with demographic variables and neuropsychological tests by education level

\begin{tabular}{|c|c|c|c|c|c|c|c|c|c|}
\hline & Education & Age & Gender & $\begin{array}{l}\text { Time in } \\
\text { The Netherlands } \\
\text { (years) }\end{array}$ & RUDAS & MMSE & $\begin{array}{l}\text { CCD objects } \\
\text { test A }\end{array}$ & $\begin{array}{l}\text { CCD objects } \\
\text { test B }\end{array}$ & $\begin{array}{l}\text { VAT } \\
\text { trial } 1\end{array}$ \\
\hline Lower than primary school & $0.586^{* *}$ & $-0.310^{*}$ & -0.019 & $-0.425^{*}$ & 0.244 & $0.532^{* *}$ & $0.576^{* *}$ & $0.608^{* *}$ & $0.672^{* *}$ \\
\hline Primary school and higher & -0.026 & $-0.409^{* *}$ & 0.200 & -0.276 & $0.640^{* *}$ & $0.678^{* *}$ & $0.630^{* *}$ & $0.686^{* *}$ & $0.712^{* *}$ \\
\hline
\end{tabular}

* Correlation is significant at the 0.05 level. ** Correlation is significant at the 0.01 level.

\section{Validity}

Intraindividual Performance on the VAT and the mVAT

The intraindividual performance of all of the participants in the first trial of the mVAT was significantly higher than in the first trial of the VAT $(Z=-3.35, p=0.001)$. The results were comparable when the controls were analyzed separately $(Z=-2.31 ; p=0.021)$ or the patients separately $(Z=-2.83 ; p=0.005)$.

\section{Discriminative Validity}

The discriminative abilities of the mVAT and VAT (first trial) for patients with dementia versus healthy controls are displayed in Figure 3. The area under the curve (AUC) was 0.95 for the mVAT $(n=36)$ and 0.88 for the VAT $(n=30)$. When discriminating patients with dementia from the entire sample (including healthy controls), the AUC for the first trial of the mVAT was good (i.e., $0.85, n=87$ ), and the AUC for the first trial of the VAT was fair (i.e., $0.77, n=80$; Figure 3). A separate analysis of only the Turkish participants revealed similar results. The sample sizes for this study were too small to examine specific dementia subtypes.

\section{Convergent Validity}

The mVAT was moderately correlated with the MMSE $(\rho=0.51, p<0.001, n=54)$, the RUDAS $(\rho=0.61, p<0.001, n=39)$, and the CCD objects test part $\mathrm{A}(\rho=0.58, p<0.001, n=$ $71)$ and part B $(\rho=0.63, p<0.001, n=70)$. The VAT showed similarly moderate correlations with these cognitive screening measures (MMSE: $\rho=0.54, p<0.001, n=49$; RUDAS: $\rho=$ $0.57, p<0.001, n=38$; CCD objects test part A: $\rho=0.57, p<0.001, n=65$; and CCD objects test part B: $\rho=0.54, p<0.001, n=64$ ). After splitting the group into a low-educated group and a highly educated group, the correlations of the mVAT with the CCD and MMSE remained similar, but the correlation with RUDAS was no longer significant in the low-educated group (Table 4).

\section{Relationship with Demographic Variables}

The mVAT was weakly correlated with education level $(\rho=0.25, p=0.02)$ and uncorrelated with gender ( $\rho=0.06, p=\mathrm{ns}$ ), as was the VAT (education: $\rho=0.29, p=0.01$; gender: $\rho=$ $0.01, p=\mathrm{ns})$. The VAT was moderately correlated with age $(\rho=-0.43, p<0.001)$ and weakly correlated with years of residence in The Netherlands $(\rho=-0.38, p<0.001)$, and the mVAT was weakly correlated with age $(\rho=-0.37, p<0.001)$ and years of residence in The Netherlands $(\rho=-0.32, p<0.01)$. After splitting the group into a low-educated and higher educated group, the correlation of the mVAT with education level and with years of residence in The Netherlands only remained significant for the low-educated group (Table 4). The correlations with age and gender remained similar. 
Franzen et al.: Assessment of Visual Association Memory with the Modified VAT

\section{Discussion}

This study showed that both the VAT and the mVAT are useful measures of visual association memory in non-Western immigrants. The mVAT, however, had a better discriminative ability and less heterogeneous item difficulty levels than the VAT.

Administration of parallel versions of the VAT and the mVAT within the same person revealed that, both for controls and for patients, higher scores were obtained on the mVAT. This finding indicates that the memory performance of non-Western immigrants may be systematically underestimated when using the original VAT with its black-and-white line drawings. This is an important finding, as memory tests for ethnic minority populations often contain visual stimuli to circumvent language barriers, and black-and-white line drawings, such as in the picture version of the Free and Cued Selective Recall Test [28] and the Location Learning Test [27, 29], are still widely used. Even some newly developed tests for illiterate and low-educated subjects contain black-and-white line drawings [30,31].

The better performance on the mVAT is best explained by the added information about the color provided by the colored photographs (as opposed to surface texture information) $[13,32]$. The added color may be particularly important for low-educated people, as the ability to decode black-and-white line drawings (such as those in the VAT) is thought to be acquired through education and literacy training $[13,33]$.

The reliability analyses indicated that only 1 item of the mVAT would have to be replaced before the mVAT could be applied in ethnic minority populations. This may seem counterintuitive, as some of the items of the mVAT do not necessarily appear to be universal. This finding may best be explained by the fact that misnamed or misidentified objects are not scored as incorrect as long as they are specific enough to be scored in the recall trial. Therefore, a hedgehog that is not recognized as such but is instead called a "brush" may have the same item difficulty as an item that seems more cross-culturally recognizable.

A remarkable finding was that performance on the mVAT was associated with education in a group of illiterate to minimally educated persons but not in a group with primary education levels and higher. This is in line with findings that even 1 year of education may substantially alter the performance on cognitive tests [7] and supports the notion of a nonlinear effect of years of education on cognitive performance [34].

A limitation of this study is that a final diagnosis could not be determined in a subset of patients. For example, in some patients it remained unclear whether the symptoms were caused by dementia, a primary psychiatric disorder, other medical conditions (e.g., diabetes and cardiovascular disease), or a combination of these factors. This seems inevitable, as diagnosing dementia in non-Western immigrants is challenging $[35,36]$ and both under- and overdiagnosis of dementia are common [37]. Strengths of this study were the relatively large sample size and the administration of both the VAT and mVAT within the same person, enabling a direct comparison between the performance on the 2 tests.

In conclusion, the mVAT is a valid, brief, and easy-to-administer test to measure visual association memory in low-educated immigrant populations. Clinicians should be aware that memory performance may be systematically underestimated when using memory tests with line drawings. Future studies with the mVAT should be aimed at including more dementia patients with a wide variety of dementia diagnoses, so the discriminative abilities can be examined for various subtypes of dementia and dementia stages.

\section{Statement of Ethics}

The study protocol has been approved by the research institute's committee on human research. 
Franzen et al.: Assessment of Visual Association Memory with the Modified VAT

\section{Disclosure Statement}

The authors have no conflict of interests to declare.

\section{Funding Sources}

This study was supported by grant 733050834 from The Netherlands Organization of Scientific Research (ZonMw Memorabel).

\section{Author Contributions}

S.F., E.v.d.B., and J.M.P. designed this study, contributed to the data collection, and drafted this paper. Y.K., L.v.d.W., M.H., R.L.v.B.-V., F.J.d.J., and L.C.J. contributed to data collection and reviewed this paper.

\section{References}

1 Ardila A 1. Cultural values underlying psychometric cognitive testing. Neuropsychol Rev. 2005 Dec;15(4): 185-95.

2 Ardila A. Toward the development of a cross-linguistic naming test. Arch Clin Neuropsychol. 2007 Mar;22(3): 297-307.

3 Ardila A, Rosselli M, Rosas P. Neuropsychological assessment in illiterates: visuospatial and memory abilities. Brain Cogn. 1989 Nov;11(2):147-66.

4 Manly JJ, Jacobs DM, Touradji P, Small SA, Stern Y. Reading level attenuates differences in neuropsychological test performance between African American and White elders. J Int Neuropsychol Soc. 2002 Mar;8(3):341-8.

5 Nielsen TR, Jørgensen K. Visuoconstructional abilities in cognitively healthy illiterate Turkish immigrants: a quantitative and qualitative investigation. Clin Neuropsychol. 2013;27(4):681-92.

6 Nielsen TR, Waldemar G. Effects of literacy on semantic verbal fluency in an immigrant population. Neuropsychol Dev Cogn B Aging Neuropsychol Cogn. 2016 Sep;23(5):578-90.

7 Ostrosky-Solis F, Ardila A, Rosselli M, Lopez-Arango G, Uriel-Mendoza V. Neuropsychological test performance in illiterate subjects. Arch Clin Neuropsychol. 1998 Oct;13(7):645-60.

8 Teng EL. Cultural and educational factors in the diagnosis of dementia. Alzheimer Dis Assoc Disord. 2002;16 Suppl 2:S77-9.

9 Lecours AR, Mehler J, Parente MA, Caldeira A, Cary L, Castro MJ, et al. Illiteracy and brain damage-1. Aphasia testing in culturally contrasted populations (control subjects). Neuropsychologia. 1987;25(1 1B):231-45.

10 Reis A, Petersson KM, Castro-Caldas A, Ingvar M. Formal schooling influences two- but not three-dimensional naming skills. Brain Cogn. 2001 Dec;47(3):397-411.

11 Reis A, Guerreiro M, Castro-Caldas A. Influence of educational level of non brain-damaged subjects on visual naming capacities. J Clin Exp Neuropsychol. 1994 Dec;16(6):939-42.

12 Rosselli M, Ardila A, Rosas P. Neuropsychological assessment in illiterates. II. Language and praxic abilities. Brain Cogn. 1990 Mar;12(2):281-96.

13 Reis A, Faísca L, Ingvar M, Petersson KM. Color makes a difference: two-dimensional object naming in literate and illiterate subjects. Brain Cogn. 2006 Feb;60(1):49-54.

14 Goudsmit M, Uysal-Bozkir Ö, Parlevliet JL, van Campen JP, de Rooij SE, Schmand B. The Cross-Cultural Dementia Screening (CCD): A new neuropsychological screening instrument for dementia in elderly immigrants. J Clin Exp Neuropsychol. 2017 Mar;39(2):163-72.

15 Goudsmit M, van Campen J, Schilt T, Hinnen C, Franzen S, Schmand B. One size does not fit all: comparative diagnostic accuracy of the Rowland Universal Dementia Assessment Scale and the Mini Mental State Examination in a memory clinic population with very low education. Dement Geriatr Cogn Disord Extra. 2018 Aug; 8(2):290-305.

16 Nielsen TR, Segers K, Vanderaspoilden V, Bekkhus-Wetterberg P, Bjørkløf GH, Beinhoff U, et al. Validation of the Rowland Universal Dementia Assessment Scale (RUDAS) in a multicultural sample across five Western European countries: diagnostic accuracy and normative data. Int Psychogeriatr. 2019 Feb;31(2):287-96.

17 Storey JE, Rowland JT, Basic D, Conforti DA, Dickson HG. The Rowland Universal Dementia Assessment Scale (RUDAS): a multicultural cognitive assessment scale. Int Psychogeriatr. 2004 Mar;16(1):13-31.

18 Nielsen TR, Andersen BB, Gottrup H, Lützhøft JH, Høgh P, Waldemar G. Validation of the Rowland Universal Dementia Assessment Scale for multicultural screening in Danish memory clinics. Dement Geriatr Cogn Disord. 2013;36(5-6):354-62. 
19 Lindeboom J, Schmand B. Visual Association Test. Leiden: PITS; 2003.

20 Lindeboom J, Schmand B, Tulner L, Walstra G, Jonker C. Visual association test to detect early dementia of the Alzheimer type. J Neurol Neurosurg Psychiatry. 2002 Aug;73(2):126-33.

21 Goudsmit M, Parlevliet JL, van Campen JP, Schmand B. Dementiediagnostiek bij oudere migranten op de geheugenpolikliniek: obstakels en oplossingen. Tijdschr Gerontol Geriatr. 2011 Oct;42(5):204-14.

22 McKhann GM, Knopman DS, Chertkow H, Hyman BT, Jack CR Jr, Kawas CH, et al. The diagnosis of dementia due to Alzheimer's disease: recommendations from the National Institute on Aging-Alzheimer's Association workgroups on diagnostic guidelines for Alzheimer's disease. Alzheimers Dement. 2011 May;7(3):263-9.

23 Román GC, Tatemichi TK, Erkinjuntti T, Cummings JL, Masdeu JC, Garcia JH, et al. Vascular dementia: diagnostic criteria for research studies. Report of the NINDS-AIREN International Workshop. Neurology. 1993 Feb;43(2):250-60.

24 Albert MS, DeKosky ST, Dickson D, Dubois B, Feldman HH, Fox NC, et al. The diagnosis of mild cognitive impairment due to Alzheimer's disease: recommendations from the National Institute on Aging-Alzheimer's Association workgroups on diagnostic guidelines for Alzheimer's disease. Alzheimers Dement. 2011 May; $7(3): 270-9$.

25 Jorm AF, Jacomb PA. The Informant Questionnaire on Cognitive Decline in the Elderly (IQCODE): socio-demographic correlates, reliability, validity and some norms. Psychol Med. 1989 Nov;19(4):1015-22.

26 Folstein MF, Folstein SE, McHugh PR. "Mini-mental state". A practical method for grading the cognitive state of patients for the clinician. J Psychiatr Res. 1975 Nov;12(3):189-98.

27 Kessels RP, Nys GM, Brands AM, van Zandvoort MJ. [The Location Learning Test as a measure of spatial memory: applicability of a modified administration procedure and normative data]. Tijdschr Gerontol Geriatr. 2004 Aug;35(4):147-52.

28 Grober E, Buschke H, Crystal H, Bang S, Dresner R. Screening for dementia by memory testing. Neurology. 1988 Jun;38(6):900-3.

29 Bucks RS, Willison JR. Development and validation of the location learning test (LLT): A test of visuo-spatial learning designed for use with older adults and in dementia. Clin Neuropsychol. 1997;11(3):273-86.

30 Maillet D, Matharan F, Le Clésiau H, Bailon O, Pérès K, Amieva H, et al. TNI-93: a new memory test for dementia detection in illiterate and low-educated patients. Arch Clin Neuropsychol. 2016 Sep. https://doi.org/10.1093/ arclin/acw065.

31 Maillet D, Narme P, Amieva H, Matharan F, Bailon O, Le Clésiau H, et al. The TMA-93: a new memory test for Alzheimer's disease in illiterate and less educated people. Am J Alzheimers Dis Other Demen. 2017 Dec;32(8): 461-7.

32 Bramão I, Reis A, Petersson KM, Faísca L. The role of color information on object recognition: a review and meta-analysis. Acta Psychol (Amst). 2011 Sep;138(1):244-53.

33 Ardila A, Bertolucci PH, Braga LW, Castro-Caldas A, Judd T, Kosmidis MH, et al. Illiteracy: the neuropsychology of cognition without reading. Arch Clin Neuropsychol. 2010 Dec;25(8):689-712.

34 Ardila A. A note of caution: normative neuropsychological test performance: effects of age, education, gender and ethnicity: a comment on Saykin et al. (1995). Appl Neuropsychol. 1998;5(1):51-3.

35 Nielsen TR, Vogel A, Riepe MW, de Mendonça A, Rodriguez G, Nobili F, et al. Assessment of dementia in ethnic minority patients in Europe: a European Alzheimer's Disease Consortium survey. Int Psychogeriatr. 2011 Feb; 23(1):86-95.

36 Nielsen TR, Andersen BB, Kastrup M, Phung TK, Waldemar G. Quality of dementia diagnostic evaluation for ethnic minority patients: a nationwide study. Dement Geriatr Cogn Disord. 2011;31(5):388-96.

37 Nielsen TR, Vogel A, Phung TK, Gade A, Waldemar G. Over- and under-diagnosis of dementia in ethnic minorities: a nationwide register-based study. Int J Geriatr Psychiatry. 2011 Nov;26(11):1128-35. 